\title{
Knowledge and Attitude toward Bariatric Surgery among Family Physicians in Cluster 2, Riyadh City, Saudi Arabia
}

\author{
Mohammed W. Alwhibi ${ }^{* 1}$, Abdulrahman M. Alfawaz ${ }^{2}$, Mohannad M. Alfakhri ${ }^{3}$, Khalid F. Alsadhan ${ }^{4}$ \\ ${ }^{1}$ Medical Resident, Department of Family and Community Medicine, King Fahad Medical City, Riyadh, Saudi \\ Arabia; MohammedAlwahibi@outlook.sa \\ ${ }^{2}$ Medical Resident, Department of Family and Community Medicine, King Fahad Medical City, Riyadh, Saudi \\ Arabia; a.m.f.1414@hotmail.com \\ ${ }^{3}$ Consultant Physician, Department of Family and Community Medicine, Security Forces Hospital, Riyadh, Saudi \\ Arabia; mohannad.alfakhri@gmail.com \\ ${ }^{4}$ Medical Resident, Department of Family and Community Medicine, King Saud University, King Saud University \\ Medical City, Riyadh, Saudi Arabia;dr.khalidfm@gmail.com
}

*Corresponding Author: Mohammed W. Alwhibi; alwhibimohammed092@gmail.com

Received 02 February 2022;

Accepted 26 January 2021;

Published 28 February 2022

\begin{abstract}
$\underline{\text { Aim: }}$ The present study aimed at investigating knowledge and attitudes towards bariatric surgery among family medicine physicians at cluster two in Riyadh city. Method: A cross-sectional study using a self-filled questionnaire was performed during the period between October and November 2021 over a study sample of 223 family medicine physicians from cluster two health care facilities in Riyadh city; namely King Fahad Medical City, Prince Mohammad Bin Abdul Aziz Hospital and the primary care centers. Data were analyzed using the SPSS software through descriptive statics and Chi-square analysis. Results: The findings of the study showed that $67.6 \%(\mathrm{n}=151)$ were able to identify cases that should be considered for bariatric surgery, $81.6 \%(\mathrm{n}=182)$ identified the safest way to perform weight loss surgery (laparoscopic), $87.9 \%$ $(n=196)$ identified the research-based evidenced outcome of surgical management of obesity (extending life expectancy with increase in quality of life) compared to conservative treatment, and $87 \%(n=184)$ identified cases that should be referred to bariatric surgery based on their body mass index (BMI) range. In addition, the findings of the study showed that family medicine physicians had positive attitudes toward bariatric surgery in term of its effectiveness and outcomes. Finally, the study found significant statistical differences in the knowledge score based on physicians' years of practice $(\mathrm{X} 2=40.9278, \mathrm{p} \leq 0.05)$. Conclusion: The study concluded that the family medicine physicians at cluster two in Riyadh city had varied level of knowledge and positive attitudes regarding bariatric surgery. The study recommended increasing family medicine physicians' knowledge and awareness regarding the benefits, consequences, techniques and rationale of bariatric surgery through engaging them in basic and advanced health education workshops and courses concerned with surgical management of obesity and metabolic disorders.
\end{abstract}

Keywords: Bariatric surgery, family medicine, Knowledge, Attitudes, Cluster Two, Riaydh.

\section{Introduction}

Obesity is considered a serious disease associated with specific morbidities and mortalities ${ }^{[1]}$. Morbidities include; hypertension, type two diabetes, obstructive sleep apnea, dyslipidemia, cardiovascular diseases, gall bladder issues and mortality occurs due to complication of medical disorders ${ }^{[2]}$. Obesity is defined as excess accumulation of body fat and its severity assessed by measuring body mass index $\left[\mathrm{BMI}=\text { weight }(\mathrm{Kg}) / \text { height }\left(\mathrm{m}^{2}\right)\right]^{[3]}$. The National Institute of Health defines morbid obesity as BMI of $35 \mathrm{~kg} / \mathrm{m}^{2}$ or greater with obesity-related comorbidity, or BMI of 40 $\mathrm{kg} / \mathrm{m}^{2}$ or greater without co-morbidity ${ }^{[4]}$. As of 2014 , the world- wide obesity among adults aged 18 and older, $11 \%$ of men and $15 \%$ of women were considered obese ${ }^{[5]}$.

In Saudi Arabia obesity is increasing with gender variations, women have a higher obesity rate compared to men. Alqarni et al, reported that $58.7 \%$ of women in Saudi Arabia are obese compared to men which are $35.1 \%$ are obese, and authors expected that the rate of obesity is claiming up to reach $59.5 \%$ by year $2022^{[6]}$.

Multidisciplinary teams and approaches are required to manage obesity and the management options depending on many factors but in general, the management of obesity includes; comprehensive lifestyle intervention, exercise, diet therapy, pharmacotherapy and surgery ${ }^{[7,8]}$. Bariatric surgery was developed 
fifty years ago to treat morbid obesity using bypass procedure, started as Jejunocolic Bypass in 1965, and since that time this kind of surgery continued to evolve until the late 1970s when the gastric banding procedure was introduced followed by gastric sleeve procedure $^{[9]}$.

Specific criteria or important points must be fulfilled to qualify an obese patient as a suitable candidate for surgical intervention; these criteria include a BMI of $35 \mathrm{~kg} / \mathrm{m}^{2}$ or greater with obesity-related comorbidities, or BMI of $40 \mathrm{~kg} / \mathrm{m}^{2}$ or greater without comorbidities ${ }^{[10]}$. Additionally, the patient should be between 18 and 60 years old in whom, an efficient alternative conservative treatment strategy had been tried, the patient is psychologically stable, cooperative and willing to follow postoperative dietary instructions, and endocrine causes of obesity were ruled out ${ }^{[11,12]}$.

The rationale of this study is to enhance and bring to the attention of family physicians regarding bariatric surgery for the treatment of morbidly obese patients. In addition, after searching on PubMed, it was found that few studies have been done globally addressing this issue, and no studies were found locally that addresse this problem.

The main objective of the present study was to explore the knowledge and attitude toward bariatric surgery among family physicians working at Cluster 2 services, Riyadh city

\section{Methods}

\section{Research Design and Setting}

The present study adopted the quantitative research approach by conducting a cross-sectional survey in the period between October and November 2021. The cross-sectional design was adopted due to its benefits in achieving the study objectives and because it is a quick and cost-effective approach. In addition, this approach explores the opinions, beliefs, knowledge, attitudes and perspectives at a specific point of time ${ }^{[13]}$.

The setting of the study was cluster two in Riyadh city. This cluster includes King Fahad Medical City (KFMC), Prince Mohammad Bin Abdul Aziz Hospital, and primary care centers. King Fahd Medical City is one of the largest and fastest developing medical complexes in the Middle East, and has a total capacity of 1200 beds, whereas Prince Muhammad Bin Abdulaziz Hospital is a 500-bed hospital that provides secondary health care services to the region located in the eastern part of Riyadh. In addition, the second cluster in Riyadh city consists of 59 primary care centers that provide primary healthcare services for the population residing in North eastern of Riyadh city.

\section{Research population}

The population of the present study consisted of all family medicine physicians registered at the Saudi Commission for Health Specialists and practicing their medical profession in the second cluster of Riyadh city $(n=234)$.

\section{Sampling and Sample Size}

The convenience sampling method was adopted to recruit the sample of the study. Convenience sampling is appropriate, quick and effective method that ensure the recruitment the highest number of participants from the study population. A convenient sample of family medicine physicians were recruited in this study. The sample size was calculated using $\mathrm{G}^{*}$ power 3.1.9.7 with related Chi-square test, a medium effect size (0.3), a significance level of (0.05), a power of 0.95 . The minimum sample size was calculated to be 220 . After the recruitment process, a total of 223 family medicine physicians were recruited for this study, with a response rate of $(95.3 \%)$.

\section{Data Collection Instrument}

The questionnaire was used as a data collection instrument in this study. The researchers developed a self-filled questionnaire that consisted of three parts. Part I was designed to elicit the family medicine physicians' sociodemographic characteristics (age, gender, area of practice, position and years of practice). In addition, Part II consisted of 13 statements measuring the family medicine physicians' bariatric surgery related knowledge. These items were closed-ended question with multiple answers. The respondent had to choose the correct answer for each statement. Moreover, part III was consisted of four items assessing the family medicine physicians' attitudes towards bariatric surgery. These four items were scales on a three-point scale (Yes, No or I don't know).

The content validity of the study questionnaire was ensured after submitting the primary version of the questionnaire to six experts (Two family medicine consultants, one endocrinology consultant, two general internal medicine consultants, and one general bariatric surgery consultant). The experts were asked to review the primary version of the questionnaire and provide their comments and feedback regarding the content of the questionnaire. A Content Validity Index (CVI) score of 0.94 was obtained, which is acceptable based on the cut-off score reported for six experts $(0.83)^{[14]}$.

Moreover, to ensure the reliability of the study questionnaire, a pilot study was performed with 15 family medicine physicians from another cluster who were not included in the study sample. The reliability of the study questionnaire was ensured using Cronbach's Alpha coefficient that was 0.86, which is considered acceptable based on the cutoff value $(0.70)$ reported by Komagamine et al ${ }^{[15]}$.

\section{Data Collection Procedure}

The data collection procedure was initiated after obtaining ethical approvals to conduct the study from the Institutional Review Board (IRB) at King Fahad Medical City (KFMC) (IRB Log number: 20536). The questionnaire was uploaded using Google forms to provide a short hyperlink that was sent to the target population through social media platforms (WhatsApp and e-mails) after the personal contact of family medicine physicians at cluster two in Riyadh city. The questionnaire was available for a period of four weeks to ensure the collection of the highest number of the study participants.

The questionnaire was designed in a way as to ensure voluntary participation of the family medicine physicians as the physician had to accept participation in the study before gaining access to the study questionnaire. The researchers ensured the privacy, confidentiality and anonymity of the study participants. In addition, data were kept in a safe hard disk that can be accessed by an alphanumeric password known only to the researchers.

\section{Data Analysis}

To analyze the responses of the study participants, the researchers used the Statistical Package of Social Sciences (SPSS v. 25.0, IBM Corp. New York, USA). Descriptive statistics were used to analyze the participants' demographic characteristics and their responses to the knowledge and attitudes statements. In addition, Chi-square analysis was used to determine the differences in the family medicine physicians' knowledge about bariatric surgeries based on their area and years of practice. A significance level of $(\alpha \leq 0.05)$ was used as a statistical significance threshold in the present study.

\section{Results}

The results presented in table (1) show that $78 \%(\mathrm{n}=174)$ of the enrolled physicians were aged 25 to 35 years, whereas $18.8 \%$ $(n=42)$ were aged 36 to 45 years and $1.8 \%(n=4)$ and $1.3 \%(n=3)$ aged 46 to 55 years and 56 years or more, respectively.

Female physicians constituted $49.3 \%(n=110)$ of the study sample, whereas male physicians constituted 50.7\% $(\mathrm{n}=113)$. About $70.4 \%(n=157)$ were practicing in King Fahad Medical City $($ KFMC), whereas $27.6 \%(n=57)$ and $4 \%(n=9)$ were practicing in 
primary care centers and Prince Mohammad bin Abdul-Aziz Hospital, respectively.

In addition, categorizing the enrolled physicians based on their position revealed that $75.3 \%(n=168)$ were medical residents, $15.7 \%(\mathrm{n}=35)$ were either registrars or senior registrars, and $9 \%$ $(n=20)$ were consultants. Moreover, it was found that $71.3 \%$ $(n=159)$ had less than 5 years of practice, $16.6 \%(n=37)$ had 5 to 10 years of practice, and $9 \%(n=20)$ and $3.1 \%(7)$ had more than 15 years of practice and 5 to 10 years of practice, respectively.

Table 1: Socio-demographic characteristics of the enrolled physicians $(n=223)$

\begin{tabular}{|c|c|c|}
\hline Variable & & $F(\%)$ \\
\hline \multicolumn{3}{|l|}{ Age } \\
\hline & 1. $25-35$ years & $174(78)$ \\
\hline & 2. $36-45$ years & $42(18.8)$ \\
\hline & 3. $46-55$ years & $4(1.8)$ \\
\hline & 4. 56 years or more & $3(1.3)$ \\
\hline \multicolumn{3}{|l|}{ Gender } \\
\hline 1. & Female & $110(49.3)$ \\
\hline 2. & Male & $113(50.7)$ \\
\hline \multicolumn{3}{|c|}{ Area of practice } \\
\hline 1. & King Fahad Medical City (KFMC) & $157(70.4)$ \\
\hline 2. & Primary Care Centers & $57(27.6)$ \\
\hline 3. & Prince Mohammad Bin Abdul-Aziz Hospital & $9(4)$ \\
\hline \multicolumn{3}{|c|}{ Position } \\
\hline 1. & Resident & $168(75.3)$ \\
\hline 2. & Consultant & $20(9)$ \\
\hline 3. & Registrar and senior registrar & $35(15.7)$ \\
\hline \multicolumn{3}{|c|}{ Years of Practice } \\
\hline & 1. Less than 5 years & $159(71.3)$ \\
\hline & 2. $5-10$ years & $37(16.6)$ \\
\hline & 3. $11-15$ years & $7(3.1)$ \\
\hline & 4. More than 15 years & $20(9)$ \\
\hline
\end{tabular}

The results presented in table (2) show that $67.7 \% \quad(n=151)$ identified that bariatric surgery should be considered for treatment of a man with a height $190 \mathrm{~cm}$, weight $128 \mathrm{~kg}$ with type 2 diabetes mellitus and a woman with a height $150 \mathrm{~cm}$, weight $80 \mathrm{~kg}$ with hypertension. However, $17.5 \%(n=39)$ reported that the bariatric surgery should be considered in man, whereas $11.7 \% \quad(n=26)$ indicated its consideration in the woman case, and $3.1 \%(n=7)$ reported that neither man nor woman should be considered for bariatric surgery.

Investigating the enrolled physicians' knowledge regarding the safest way to perform weight loss surgery based on reported scientific evidence indicated that $81.6 \% \quad(\mathrm{n}=182)$ answered correctly that laparoscopic; minimal invasive technique also known as "keyhole surgery" was the safest one, whereas $9.9 \%(n=22)$ reported that endoscopic; allowing access to the abdominal cavity through natural orifice such as mouth, anus, is the safest way. In addition, it was found that $1.3 \%(n=3)$ reported that laparotomy; a wide opening of abdominal cavity to allow precise insight into it is the safest research-evidenced way to perform weight loss surgery. However, $7.2 \%(n=16)$ reported that none of the above ways is evidenced to be a safe way to lose weight surgically.

Moreover, it was found that $87.9 \%$ (196) of the enrolled physicians correctly identified that surgical management of obesity in comparison to conservative treatment leads to an extension of life expectancy with increased quality of life, whereas $6.7 \%(n=15)$ reported that it leads to extending life expectancy with reduced in quality of life, $3.1 \%(n=7)$ reported that it leads to shortening life expectancy with reduced in quality of life, and $2.2 \% \quad(n=5)$ considered that surgical treatment leads to shortening life expectancy with increased quality of life.

Furthermore, about $76.2 \% \quad(n=170)$ of the enrolled physicians reported that surgical management of obesity leads to reduction in health care costs for patient suffering from obesity, whereas $7.2 \% \quad(n=16)$ reported that the surgical management of obesity leads to an increase in health care costs for patient suffering from obesity, and $6.3 \% \quad(n=14)$ reported that the surgical management of obesity doesn't affect the health care costs for patient suffering from obesity. However, 10.3\% ( $\mathrm{n}=23)$ reported that the above issue has not been yet investigated.

Exploring the enrolled physicians' knowledge regarding the best surgical option for producing decrease in obesity related co-morbidities especially in diabetes mellitus patients, based on research evidences revealed that $30 \%(n=67)$ answered correctly that both Roux-en-Y Gastric Bypass and Sleeve gastrectomy are the best surgical options. However, 48\% $(\mathrm{n}=107)$ considered adjusted gastric banding as the best, $18.4 \%(n=41)$ answered that Roux-en-Y Gastric Bypass (RYGB) is the best, and 3.6\% ( $\mathrm{n}=8)$ answered that sleeve gastrectomy is the best surgical option to decrease obesity-related co-morbidities especially in diabetes mellitus patients.

With regard to the bariatric surgery of choice for patients with Barrett's esophagus and uncontrolled severe gastro-esophageal reflux disease (GERD), about 55.2\% ( $\mathrm{n}=123)$ answered correctly that Roux-en-Y Gastric Bypass (RYGB) is the surgery of choice, whereas $21.1 \%(n=47)$ considered that sleeve gastrectomy is the bariatric surgery of choice, $14.3 \% \quad(n=32)$ responded that both sleeve gastrectomy and adjusted gastric banding together are the surgeries of choice, and $9.4 \%(n=21)$ reported that adjusted gastric banding is the surgery of choice.

Assessing the enrolled physicians' knowledge regarding the form of post-operative thromboprophylaxis that is appropriate for post-bariatric surgery revealed that $47.1 \%(n=105)$ answered correctly that low molecular weight heparin (LMWH) is the appropriate form, whereas $12.1 \% \quad(n=27)$ reported that thromboembolic device stockings (TEDS) is the form of choice, and $7.2 \% \quad(n=16)$ reported that thromboprophylaxis should be adopted only if the patient has a history of venous thromboembolism. However, $33.6 \%(n=75)$ reported that no forms of post-operative thromboprophylaxis should be used if the patient is adequately mobilizing.

Investigating the enrolled physicians' knowledge regarding the recommended period of avoiding conception after bariatric surgery based on the American Association of Clinical Endocrinologists, the Obesity Society, and the American Society 
for Metabolic \& Bariatric Surgery recommendations revealed that $33.2 \%(n=74)$ answered correctly that this period should be 12 to 18 months, whereas $38.1 \%(\mathrm{n}=85), 16.1 \% \quad(\mathrm{n}=36)$ and $12.6 \%$ $(n=28)$ reported that this period should be 6 to 12 months, 3 to 6 months, and 18 to 24 months, respectively.

The mortality rate of Roux-en-Y was correctly identified by $48 \%(n=107)$. On the other hand, $26 \%(n=58)$ reported that the mortality rate is $2 \%, 20.2 \%(\mathrm{n}=45)$ reported that $1 \%$ is the mortality rate of Roux-en-Y, and only $5.8 \%(\mathrm{n}=13)$ reported that $4 \%$ is the mortality rate of Roux-en-Y.

Investigating the enrolled physicians' knowledge regarding the post-operative liquid diet period for individuals subjected to bariatric surgery revealed that $54.7 \%(n=122)$ answered correctly that two weeks is the post-operative liquid diet period, whereas $30.5 \%(\mathrm{n}=68)$ reported that this period should be 4 weeks, and $13.9 \%(n=31)$ and $0.9 \%(n=2)$ reported that 8 weeks and more than 8 weeks is the post-operative liquid diet period, respectively.

About $70.4 \%(\mathrm{n}=157), 10.8 \%(\mathrm{n}=24)$ and $5.8 \%(\mathrm{n}=13)$ reported that individuals should be referred for bariatric surgery in case of a BMI value of: $\geq 35$ and $\leq 39.9$ with obesity-related comorbidity, $\mathrm{BMI} \geq 50$, and $\mathrm{BMI} \geq 40$, respectively. However, $6.3 \%(\mathrm{n}=14)$ indicated that an individual with $\mathrm{BMI} \geq 35$ and $\leq 39.9$ with no obesity-related comorbidity should be referred for bariatric surgery, $5.8 \%(\mathrm{n}=13)$ reported that an individual with $\mathrm{BMI} \geq 30$ and $\leq 34.9$ with no obesity-related comorbidity is the individual who should be referred for bariatric surgery, and only $0.9 \quad(n=2)$ reported that if an individual's BMI $\geq 30$ and $\leq 34.9$ with obesityrelated comorbidity, then he/she should be referred for bariatric surgery.

Finally, it was found that $15.2 \% \quad(n=34)$ of the enrolled physicians were satisfied with their knowledge about surgical treatment of obesity, whereas $7.6 \%(n=17)$ were very satisfied and $55.6 \%(n=124)$ had a neutral satisfaction level concerning their level of knowledge related to treatment of obesity using surgical procedures. On the other hand, the results showed that $21.1 \%$ $(n=47)$ and $0.4 \% \quad(n=1)$ were either dissatisfied and very dissatisfied, respectively.

Table 2: Enrolled physicians responses to knowledge items (n=223)

\begin{tabular}{|c|c|}
\hline Item & $F(\%)$ \\
\hline $\begin{array}{l}\text { In which of the following patients, bariatric surgery should be considered as a treatment option } \\
\text { A man: height } 190 \mathrm{~cm} \text {, weight } 128 \mathrm{~kg} \text { with type } 2 \mathrm{DM} \\
\text { A woman: height } 150 \mathrm{~cm} \text {, weight } 80 \mathrm{~kg} \text { with } \mathrm{HTN} \text {. } \\
\text { 1. The man } \\
\text { 2. The woman } \\
\text { 3. Both* } \\
\text { 4. None of the above patients }\end{array}$ & $\begin{array}{l}39(17.5) \\
26(11.7) \\
151(67.7) \\
7(3.1)\end{array}$ \\
\hline $\begin{array}{l}\text { Which of the following techniques, in accordance to the scientific evidence, is considered the safest way to perform } \\
\text { weight loss surgery? } \\
\text { a) Laparotomy; a wide opening of abdominal cavity to allow precise insight into it. } \\
\text { b) Laparoscopic; minimal invasive technique also known as "keyhole surgery ".* } \\
\text { c) Endoscopic; allowing access to the abdominal cavity through natural orifice such as mouth, anus. } \\
\text { d) None of the above. }\end{array}$ & $\begin{array}{l}3(1.3) \\
182(81.6) \\
22(9.9) \\
16(7.2)\end{array}$ \\
\hline $\begin{array}{l}\text { 3. According to results published in recent years, surgical management of obesity in comparison to conservative } \\
\text { treatment leads to: } \\
\text { a) Shorting life expectancy with reduced in quality of life. } \\
\text { b) Extending life expectancy with increase in quality of life.* } \\
\text { c) Extending life expectancy with reduced in quality of life. } \\
\text { d) Shorting life expectancy with increase in quality of life. }\end{array}$ & $\begin{array}{l}7(3.1) \\
196(87.9) \\
15(6.7) \\
5(2.2)\end{array}$ \\
\hline $\begin{array}{l}\text { 4. Surgical management of obesity lead to: } \\
\text { a) Increasing the risk of cancer. } \\
\text { b) Decreasing the risk of cancer.* } \\
\text { c) Doesn't affect the risk of cancer. } \\
\text { d) The impact on cancer risk has been established, but so far insufficient scientific evidence to conclude if surgical } \\
\text { treatment of obesity leads to decreasing or increasing of it. }\end{array}$ & $\begin{array}{l}2(0.9) \\
39(17.5) \\
61(27.4) \\
121(54.3)\end{array}$ \\
\hline $\begin{array}{l}\text { 5. Surgical management of obesity lead to: } \\
\text { a) An increase in health care costs for patient suffering from obesity. } \\
\text { b) A reduction in health care costs for patient suffering from obesity.* } \\
\text { c) Doesn't affect the health care costs for patient suffering from obesity. } \\
\text { d) The above issue has not been yet investigated. }\end{array}$ & $\begin{array}{l}16(7.2) \\
170(76.2) \\
14(6.3) \\
23(10.3)\end{array}$ \\
\hline $\begin{array}{l}\text { 6. Which of the following procedure, according to the evidence, considered as the best surgical option to decrease } \\
\text { obesity related co-morbidities especially in diabetes mellitus patients: } \\
\text { a) Roux-en-Y Gastric Bypass (RYGB). } \\
\text { b) Adjusted gastric banding. } \\
\text { c) Sleeve gastrectomy. } \\
\text { d) Roux-en-Y Gastric Bypass and Sleeve gastrectomy.* }\end{array}$ & $\begin{array}{l}41(18.4) \\
107(48) \\
8(3.6) \\
67(30)\end{array}$ \\
\hline $\begin{array}{l}\text { 7. Which of the following bariatric surgery considered the surgery of choice for patient with Barrett's esophagus } \\
\text { and uncontrolled severe GERD: } \\
\text { a) Roux-en-Y Gastric Bypass (RYGB). * } \\
\text { b) Sleeve gastrectomy. } \\
\text { c) Adjusted gastric banding. } \\
\text { d) Sleeve gastrectomy and adjusted gastric banding. }\end{array}$ & $\begin{array}{l}123(55.2) \\
47(21.1) \\
21(9.4) \\
32(14.3)\end{array}$ \\
\hline $\begin{array}{l}\text { 8. What form of post-operative thromboprophylaxis do you think is appropriate for post-bariatric surgery? } \\
\text { a) Thromboembolic Device Stockings (TEDS). } \\
\text { b) Low molecular weight heparin (LMWH).* }\end{array}$ & $\begin{array}{l}27(12.1) \\
105(47.1)\end{array}$ \\
\hline
\end{tabular}


c) Only if the patient has a history of venous thromboembolism.

$16(7.2)$

d) None if the patient mobilizing adequately.

$75(33.6)$

9. American Association of Clinical Endocrinologists, the Obesity Society, and the American Society for Metabolic

\& Bariatric Surgery recommended that women avoid conception for months after bariatric surgery:

a) 3 to 6 months.

b) 6 to 12 months.

c) 12 to 18 months. *

d) 18 to 24 months.

10. What is the correct mortality rate of Roux-en-Y?
a) $0.1 \% *$
b) $1 \%$
c) $2 \%$
d) $4 \%$

11. In your opinion, how long should post-operative bariatric surgery patients be on a liquid diet?
a) 2 weeks.*
b) 4 weeks.
c) 8 weeks.
d) More than 8 weeks.

13. In your opinion, who should be referred for consideration of bariatric surgery as the primary treatment? (you can choose more than one)

a) BMI of: $\geq 30$ and $\leq 34.9$ with no obesity related comorbidity.

b) BMI of: $\geq 30$ and $\leq 34.9$ with obesity related comorbidity.

c) BMI of: $\geq 35$ and $\leq 39.9$ with no obesity related comorbidity.

$107(48)$

$45(20.2)$

$58(26)$

$13(5.8)$

d) BMI of: $\geq 35$ and $\leq 39.9$ with obesity related comorbidity.*

e) BMI of: $\geq 40 . *$

f) BMI of: $\geq 50$. $^{*}$

14. How do you assess your knowledge about surgical treatment of obesity?
a) Very satisfied.
b) Satisfied.
c) Natural.
d) Unsatisfied.
e) Very unsatisfied.

*Correct answer

The results presented in table (3) show the frequencies and percentages of the enrolled physicians' responses to the scale items exploring their attitudes towards bariatric surgery. The results indicate that $91 \%(n=203)$ reported that they heard that diabetes can be controlled by bariatric surgery. In addition, it was found that $71.7 \%(\mathrm{n}=160)$ thought that ideal weight loss could be achieved through bariatric surgery, whereas $22.4 \%(n=50)$ disagreed with this idea. Moreover, $81.2 \% \quad(\mathrm{n}=181)$ believed that surgical treatment of obesity and metabolic disorders is safe and reliable, whereas $7.2 \%(\mathrm{n}=16)$ disagreed with this idea. Finally, it was found that $81.6 \%(n=182)$ reported that they would recommend bariatric surgery if a family member or a friend had class III obesity or metabolic diseases, whereas $1 \mathrm{~s} 2.6 \%(\mathrm{n}=28)$ would not recommend bariatric surgery in this case and $5.8 \%(n=13)$ did not know whether or not to recommend bariatric surgery in such a case.

Table 3: Enrolled physicians attitudes towards bariatric surgery $(n=223)$

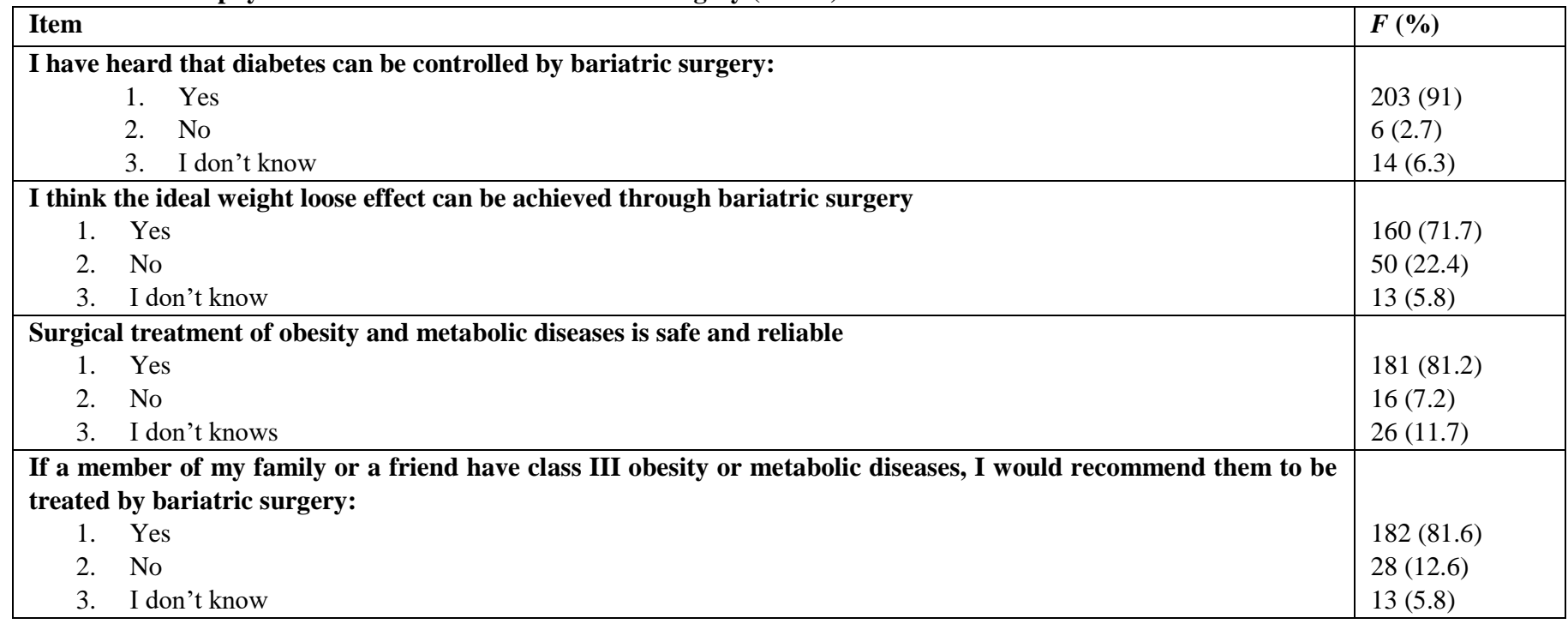

The results presented in table (4) represent the Chi-square analysis for identifying the differences in physicians' knowledge about bariatric surgeries based on their field and years of practice. The results showed that there was no significant difference in physician's knowledsge about bariatric surgery based on their area of practice $(\mathrm{X} 2=3.0427, \mathrm{p}=0.22)$, whereas a significant difference in the physicians' knowledge about bariatric surgery reflected differences in their years of practice $(X 2=40.9278, \mathrm{p} \leq 0.05)$. 
Table 4: Chi-square analysis for the differences in knowledge about bariatric surgery based on physicians' area and years of practice

\begin{tabular}{|c|c|c|c|c|}
\hline Item & \multicolumn{2}{|c|}{ Knowledge response } & \multirow[b]{2}{*}{$\mathrm{X}^{2}$} & \multirow[b]{2}{*}{$\mathbf{p}$} \\
\hline & $\begin{array}{l}\text { Correct } \\
\text { (1530) }\end{array}$ & $\begin{array}{l}\text { Incorrect } \\
\text { (1146) }\end{array}$ & & \\
\hline $\begin{aligned} \text { Area of practice } & \\
\text { 1. } & \text { King Fahad Medical City (KFMC) } \\
\text { 2. } & \text { Primary Care Centers } \\
3 . & \text { Prince Mohammad Bin Abdul-Aziz Hospital }\end{aligned}$ & $\begin{array}{l}1059(69.2) \\
403(26.3) \\
68(4.5)\end{array}$ & $\begin{array}{l}825(72) \\
281(24.5) \\
40(3.5)\end{array}$ & 3.043 & 0.22 \\
\hline $\begin{array}{l}\text { Years of Practice } \\
\begin{aligned} & \text { 1. } \text { Less than } 5 \text { years } \\
& 2 . 5-10 \text { years } \\
& 3 . 11-15 \text { years } \\
& \text { 4. } \text { More than } 15 \text { years } \\
&\end{aligned}\end{array}$ & $\begin{array}{l}1082(70.7) \\
248(16.2) \\
66(4.3) \\
134(8.8)\end{array}$ & $\begin{array}{l}826(72.1) \\
196(17.1) \\
18(1.6) \\
106(9.2) \\
\end{array}$ & 40.93 & $\leq 0.05^{*}$ \\
\hline
\end{tabular}

*Significant at significance level $(\alpha \leq 0.05)$

\section{Discussion}

Diet and exercise are the first steps for treating obesity. However, once an individual reached the point at which he/she qualifies for bariatric surgery, it is extremely difficult to lose weight that the patient needs to lose become a healthier individual through just diet and exercise. Medications are another tool to treat obesity ${ }^{[16]}$. However, these medications require monitoring and they do have some side effects, and there is only a short period of time to be taken. Unfortunately, some people experience weight regain once they stopped their medications ${ }^{[17]}$.

Basically, once an individual becomes about 80 pounds overweight (BMI $\geq 40$ ), this individual qualified for bariatric surgery. In addition, an individual with a BMI $\geq 35$ with medical comorbidities such as diabetes, high blood pressure, andlor sleep apnea, also qualifies for bariatric surgery ${ }^{[18]}$. The present study aimed at exploring the knowledge and attitudes of family medicine physicians toward bariatric surgery through recruitment of a sample of family medicine physicians from cluster two in Riyadh city.

The findings of the present study showed that about two thirds of family medicine physicians in cluster two at Riyadh city were able to identify the cases qualified for bariatric surgery. In addition, it was found that most of the enrolled physicians identified the safest way to perform weight loss surgery based on reported research-based evidence. Moreover, a great majority of the enrolled physicians correctly reported the outcome of the surgical management of obesity compared to the conservative treatment. However, a very low level of knowledge regarding the association of surgical management of obesity and cancer as less than one fifth of the enrolled physicians who correctly reported that surgical management of obesity can lead to a decrease in the risk of cancer. The variation in this knowledge level could be attributed to the lack of available research-based evidences about the benefits, consequences, and techniques of bariatric surgeries, which is discussed by Aikenhead et al ${ }^{[19]}$ who described that variations in guidelines and evidence related to bariatric surgery were significantly and affect the available knowledge about bariatric surgery.

Our findings suggest that family medicine physicians in cluster two at Riyadh city had a good knowledge that surgical management of obesity leads to a reduction in healthcare costs for patients suffering from obesity. About one-third of the study participants correctly reported that both Roux-en-Y Gastric Bypass and sleeve gastrectomy are the best surgical options to decrease obesity-related comorbidities, especially in diabetic patients. However, more than half of the enrolled physicians were able to identify Roux-en-Y Gastric Bypass (RYGB) as the surgery of choice for patients with Barrett's esophagus and uncontrolled severe GERD. On a similar level, about half of the enrolled physicians were able to identify the form of post-operative thromboprophylaxis that is appropriate for post-bariatric surgery, which is Low Molecular Weight Heparin (LMWH). These findings might be referred to the huge literature and knowledge related to the nutritional, endocrine and metabolic, bone loss, normal flora growth and many other consequences that are still under research. In addition, the low levels of knowledge might be referred to the lack of information resources that could be used to retrieve valid and relsiable information about the benefits, consequences and outcomes of the bariatric surgery.

Furthermore, about one third of the enrolled physicians were able to respond correctly to the length of conception avoidance among females who underwent bariatric surgery based on recommendations of the American Association of Clinical Endocrinologists, the Obesity Society, and the American Society for Metabolic \& Bariatric Surgery (12-18 months). These findings are in accordance with the findings reported by Alqahtani et al ${ }^{[20]}$ who found that Saudi physicians had low level of knowledge about the pregnancy avoidance period for women who underwent bariatric surgery.

In addition, more than half of them correctly identified the mortality rate of Roux-en-Y $(0.1 \%)$ and the length of the period the patient should be consuming a liquid diet after being subject to bariatric surgery (two weeks). These findings are supported with the findings reported by Sertaç et al ${ }^{[21]}$ who found that Turkish patients had a low level of knowledge regarding bariatric surgery. However, the context of the study is different as the sample of the study in Sertaç et al ${ }^{[21]}$ that consisted of patients rather than physicians.

The findings of the study showed that most of the enrolled physicians were able to determine what cases should be referred for bariatric surgery as the primary treatment. Furthermore, about one quarter of the enrolled physicians were satisfied about their knowledge level. These findings could be attributed to the increased prevalence of bariatric surgery cases, especially in Saudi Arabia, which recorded more than 30.000 bariatric surgery cases in $2019^{[22]}$.

The findings of the study related to family medicine physicians' knowledge about bariatric surgery could be best described as varied depending on the aspect of the bariatric surgery, for example. family medicine residents were able to identify the cases qualified for bariatric surgery, whereas a low level of knowledge regarding the consequences of bariatric surgery and the safe, best and most appropriate techniques of bariatric surgery was found.

The findings of the study reveal that a high majority of the enrolled family medicine physicians knew that diabetes mellitus can be controlled through bariatric surgery, ideal weight loss can be achieved through bariatric surgery, and surgical treatment of obesity and metabolic diseases is safe and reliable, they would recommend bariatric surgery to a family member or a friend with class III obesity. These findings are referred to the increasing and successful cases in Saudi Arabia and positive outcomes demonstrated by the positive perception that are reported in 
different studies, such as Alghutayghit et al ${ }^{[23]}$ and Alfadhel et al ${ }^{[24]}$ who reported an increased in-public and healthcare workers' perceptions towards bariatric surgeries.

Finally, it was found that the level of family medicine residents' knowledge significantly correlates with years of practice. This result might reflect that increased years of practical experience indicates higher knowledge and higher involvement in educational and awareness campaigns and workshops offered by different medical institutions.

Despite the significant findings reported in the present study, still several limitations that might limit the generalization of the study findings. These limitations include the limited psychometric properties of the study questionnaire, as this questionnaire had no cut-off score to assess the levels of knowledge and attitudes regarding bariatric surgery among family medicine physicians. In addition, geographical limitations might affect the validity and reliability of the study findings since this study was performed in cluster two healthcare facilities in Riyadh city, Saudi Arabia. Therefore, these findings might not be valid for other geographical zones in Saudi Arabia due to differences in the level of healthcare services and facilities in these zones.

\section{Conclusion}

The present study sought to explore the knowledge and attitudes of family medicine physicians towards bariatric surgery. The study concluded that Saudi family medicine physicians' in cluster two at Riyadh city have good knowledge about identifying cases that should be considered for bariatric surgery, and about the best and safe bariatric surgery techniques. In addition, the study concluded that family medicine physicians have positive attitudes toward bariatric surgery, its effectiveness in controlling metabolic disorders, and recommending relatives or friends to bariatric surgery if needed.

Based on the findings reported in the present study, the study recommends improving family medicine physicians' knowledge and attitudes toward bariatric surgery by engaging them in tailored educational sessions about bariatric surgery, its techniques, effectiveness, rationale, and outcomes. In addition, the study recommends conducting further research using scaled data collection tools to quantitatively assess the family medicine physicians' levels of knowledge and attitudes toward bariatric surgery.

\section{Ethical Approval}

The present study was approved by the Institutional Review Board (IRB) at King Fahad Medical City (KFMC) (IRB Log number: 20536).

\section{Conflict of Interest}

The authors declare no conflict of interest

\section{Funding}

This research is not funded

\section{Author contribution}

The authors declare that all authors had equally participated in the final production of the current manuscript. The authors equally formulated the theoretical and conceptual frameworks, designed the methodological procedure, performed the data collection process, analyzed and processed the data, interpreted the data and drawn the conclusions, and finalized the research manuscript.

\section{Acknowledgment}

The authors would like to extend their gratitude to the physicians who participated in the data collection process for their valuable time filling in the questionnaire of the study. In addition, the authors are thankful to the administrative authorities in King Fahad Medical City, the primary care centers in Riyadh city and Prince Mohammad Bin Abdul Aziz Hospital for facilitating the data collection process in their healthcare facilities. Finally, sincere thanks for Dr. Saleh Alrajhi, Dr. Ahmed Almujil, Dr. Nassren Alfaris, Dr. Suleiman Hamed, Dr. Mohamed Essawy and Dr. Mohammed Aljabali for their precious time in reviewing and validating the study questionnaire.

\section{References}

[1] Abdelaal M, le Roux CW, Docherty NG. Morbidity and mortality associated with obesity. Annals of translational medicine. 2017;5(7).

[2] Pozza C, Isidori AM. What's behind the obesity epidemic. Imaging in bariatric surgery: Springer; 2018. p. $1-8$.

[3] Nuttall FQ. Body mass index: obesity, BMI, and health: a critical review. Nutrition today. 2015;50(3):117.

[4] Aminian A, Chang J, Brethauer SA, Kim JJ. ASMBS updated position statement on bariatric surgery in class I obesity (BMI 30-35 kg/m2). Surgery for Obesity and Related Diseases. 2018;14(8):1071-87.

[5] Lim HJ, Xue H, Wang Y. Global trends in obesity. Handbook of Eating and Drinking: Interdisciplinary Perspectives. 2020:1217-35.

[6] Saad MA. A review of prevalence of obesity in Saudi Arabia. J Obes Eat Disord. 2016;2(2):1-6.

[7] Montesi L, El Ghoch M, Brodosi L, Calugi S, Marchesini G, Dalle Grave R. Long-term weight loss maintenance for obesity: a multidisciplinary approach. Diabetes, metabolic syndrome and obesity: targets and therapy. 2016;9:37.

[8] Bischoff SC, Boirie Y, Cederholm T, Chourdakis M, Cuerda C, Delzenne NM, et al. Towards a multidisciplinary approach to understand and manage obesity and related diseases. Clinical nutrition. 2017;36(4):917-38.

[9] Welsh LK, Murayama KM. History of Bariatric Surgery. Endoscopy in Obesity Management: Springer; 2018. p. $1-11$.

[10] Cummings DE, Cohen RV. Bariatric/Metabolic Surgery to Treat Type 2 Diabetes in Patients With a BMI <35 kg/m2. Diabetes care. 2016;39(6):924-33.

[11] Bak M, Seibold-Simpson SM, Darling R. The potential for cross-addiction in post-bariatric surgery patients: Considerations for primary care nurse practitioners. Journal of the American Association of Nurse Practitioners. 2016;28(12):675-82.

[12] Bland CM, Quidley AM, Love BL, Yeager C, McMichael B, Bookstaver PB. Long-term pharmacotherapy considerations in the bariatric surgery patient. American Journal of Health-System Pharmacy. 2016;73(16):1230-42.

[13] Pandey P, Pandey MM. Research Methodology Tools and Techniques. Bridge Center; 2021.

[14] Polit DF, Beck CT, Owen SV. Is the CVI an acceptable indicator of content validity? Appraisal and recommendations. Research in nursing \& health. 2007;30(4):459-67.

[15] Komagamine Y, Kanazawa M, Kaiba Y, Sato Y, Minakuchi S. Reliability and validity of a questionnaire 
for self-assessment of complete dentures. BMC oral health. 2014;14(1):1-7.

[16] Hannah WN, Harrison SA. Effect of weight loss, diet, exercise, and bariatric surgery on nonalcoholic fatty liver disease. Clinics in liver disease. 2016;20(2):339-50.

[17] Kapoor E, Collazo-Clavell ML, Faubion SS, editors. Weight gain in women at midlife: a concise review of the pathophysiology and strategies for management. Mayo Clinic Proceedings; 2017: Elsevier.

[18] Khalid SI, Omotosho PA, Spagnoli A, Torquati A. Association of bariatric surgery with risk of fracture in patients with severe obesity. JAMA network open. 2020;3(6):e207419-e.

[19] Aikenhead A, Lobstein T, Knai C. Review of current guidelines on adolescent bariatric surgery. Clinical obesity. 2011;1(1):3-11.

[20] Alqahtani N, Alkhudairi SS, Aljahli MS, Alshammari IB, Almansour BT, Alshayeb SN. Awareness and knowledge of the obstetric and gynecological impact of bariatric surgery among women in the Eastern Province of Saudi Arabia. Journal of family medicine and primary care. 2019;8(11):3678.

[21] Güler SA, Y1lmaz TU, Şimşek T, Yirmibeşoğlu O, Kırnaz S, Utkan NZ, et al. Obesity and Bariatric Surgery awareness in the Kocaeli province, a leading industrial city in Turkey. Turkish journal of surgery. 2018;34(3):165.

[22] Alwajeeh SA, Alasmari RS, Alattas IM, Hassan RAA, Alrawaji RI. Bariatric surgeries' complications in Saudi Arabia. Saudi Journal of Laparoscopy. 2020;5(1):1.

[23] Alghutayghit AK, Alanazi AM, Abdelfatah H, Elhady SAA, Alsulami GM, Alomair AM, et al. Assessment of public perception and attitude regarding obesity and bariatric surgery in Aljouf region, Saudi Arabia. Age.18(25):158.

[24] Alfadhel SF, Almutairi HS, Al Darwish TH, Almanea LT, Aldosary RA, Shook AH. Knowledge, attitude, and practice of bariatric surgery among adult Saudi community, Saudi Arabia, 2019. Journal of Family Medicine and Primary Care. 2020;9(6):3048.

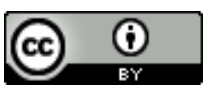

Open Access This article is licensed under a Creative Commons Attribution 4.0 International License, which permits use, sharing, adaptation, distribution and reproduction in any medium or format, as long as you give appropriate credit to the original author(s) and the source, provide a link to the Creative Commons license, and indicate if changes were made. The imagses or other third party material in this article are included in the article's Creative Commons license, unless indicated otherwise in a credit line to the material. If material is not included in the article's Creative Commons license and your intended use is not permitted by statutory regulation or exceeds the permitted use, you will need to obtain permission directly from the copyright holder. To view a copy of this license, visit https://creativecommons.org/licenses/by/4.0/.

(C) The Author(s) 2021 